Canadian University Music Review

Canadian University Music Review

Revue de musique des universités canadiennes

\title{
Le chant de Kathinka
}

comme Requiem de Lucifer pour flûte et six percussionnistes

\section{Karlheinz Stockhausen}

Numéro 4, 1983

URI : https://id.erudit.org/iderudit/1013894ar

DOI : https://doi.org/10.7202/1013894ar

Aller au sommaire du numéro

\section{Éditeur(s)}

Canadian University Music Society / Société de musique des universités canadiennes

\section{ISSN}

0710-0353 (imprimé)

2291-2436 (numérique)

Découvrir la revue

\section{Citer ce document}

Stockhausen, K. (1983). Le chant de Kathinka : comme Requiem de Lucifer pour flûte et six percussionnistes. Canadian University Music Review / Revue de musique des universités canadiennes, (4), 6-8. https://doi.org/10.7202/1013894ar

(c) Canadian University Music Society / Société de musique des universités canadiennes, 1983
Ce document est protégé par la loi sur le droit d'auteur. L'utilisation des services d'Érudit (y compris la reproduction) est assujettie à sa politique d'utilisation que vous pouvez consulter en ligne.

https://apropos.erudit.org/fr/usagers/politique-dutilisation/ 


\title{
LE CHANT DE KATHINKA comme Requiem de Lucifer pour flûte et six percussionnistes
}

\author{
Karlheinz Stockhausen
}

En réponse à notre demande d'hommage à Claude Vivier pour ce numéro, Karlheinz Stockhausen qui a été son professeur à Cologne, nous a proposé de publier les explications entourant son "Chant de Kathinka ». "Lorsque cette œuvre sera créée à Donaueschingen le 15 octobre 1983, nous écrit-il, l'âme de Claude Vivier sera sûrement à l'écoute ».

Le "Chant de Kathinka » constitue la deuxième scène de l'opéra Samedi de Lumière.

On peut l'interpréter séparément,

- soit en version scénique,

- soit en version de concert.

Pour les exécutions de concert, on peut enregistrer les percussions à six canaux et les diffuser par haut-parleurs pendant le jeu de la flûte.

Le titre alors de l'oeuvre se lit:

Le Chant ...

pour flûte et bande magnétique.

On peut aussi interpréter l'ouvre pour flûte seule.

Une version pour flûte et musique électronique est publiée séparément et porte le titre de 
Le Chant ...

pour flûte et musique électronique.

Contenu :

Samedi de Lumière (jour de Saturne) est le jour de Lucifer. Jour de la mort, nuit du passage à la lumière.

Tout comme Lucifer, tout homme, enchanté et séduit par la nature sensible de la musique de la vie, meurt d'une mort apparente. Ainsi le Requiem de Lucifer est-il le Requiem pour tout homme qui cherche la lumière éternelle.

Le Chant de Kathinka préserve l'âme du défunt contre la tentation moyennant des exercices musicaux auxquels celle-ci tend l'oreille régulièrement pendant quarante neuf jours après la mort corporelle, et la conduit à la conscience claire.

Pour se préparer à la mort on peut apprendre pendant la vie à percevoir correctement ces exercices.

KATHINKA: KAT (chat, l'animal du samedi)

THINK (penser, considérer)

A (Alif-alpha, le commencement, l'origine)

Kathinka chante avec flûte et voix.

Six percussionistes - les six sens mortels - reproduisent à l'aide de plaques sonores et d'« instruments magiques " les résonances

1 de la vue

2 de l'ouïe

3 de l'odorat

$4 \mathrm{du}$ goût

5 du toucher

6 de la pensée.

Le Chant de Kathinka débute par une salutation.

Ensuite on y instruit l'âme à travers $2 \times 11$ exercices et deux pauses en vingt-quatre étapes qui constituent un processus unifié et qui sont clairement indiqués par des signaux du «fa » aigu dans la partition. 
A ces exercices s'enchaînent

a) le renvoi des sens

b) la sortie

c) les onze sons du trombone

d) le cri.

a) L'un après l'autre on prend congé des six sens, dans l'ordre suivant : le goût, la vue, le toucher, l'odorat, la pensée et l'ouïe.

b) Pendant la sortie, les dernières respirations se transforment lentement en un rire discret qui s'éteint.

c) Tout en se métamorphosant dans les onze sons du trombone, qui sont au coeur de la ritournelle de Lucifer telle que la flûte l'émettait à la fin du chant de Kathinka.

d) Le cri signifie-t-il la libération d'une renaissance, l'extinction perpétuelle ou l'entrée dans la clarté de la lumière? La décision en appartient à l'âme elle-même.

Le Chant de Kathinka comme Requiem de Lucifer conduit les âmes des défunts à travers l'écoute jusqu'à la conscience claire.

Si on désire jouer le Requiem de Lucifer pour secourir un défunt, on devra alors l'exécuter périodiquement chaque jour deux, trois, quatre ou plusieurs fois encore, pendant les quarante neuf jours qui suivent la mort corporelle, et cela avec flûte et percussions, ou flûte et bande magnétique, ou flûte et musique électronique, ou simplement avec la flûte seule.

Le Chant de Kathinka comme Requiem de Lucifer a été composé en février et mars 1983, en collaboration avec la flûtiste Kathinka Pasveer et lui est dédié. Elle créera la version de concert pour flûte et percussions le 15 octobre 1983 dans le cadre des Journées de musique nouvelle de Donaueschingen, et la version scénique (ainsi que neuf autres exécutions publiques) dans le contexte de l'opéra Samedi de Lumière du 15 au 26 mai 1984 à La Scala de Milan. 